\title{
Raman Spectroscopic Study on the Structure of Silicate Slag*
}

\author{
By Shigeki KASHIO, ,* Yasutaka IGUCHI, ,** Takenari GOTO,**** \\ Yuichiro NISHIN $A^{* * * * *}$ and Tasuku FUWA A***** $^{* * *}$
}

\begin{abstract}
Synopsis
A Raman spectral study on the structure of binary silicates, $\mathrm{Li}_{2} \mathrm{O}$ $\mathrm{SiO}_{2}, \mathrm{Na}_{2} \mathrm{O}-\mathrm{SiO}_{2}, \mathrm{~K}_{2} \mathrm{O}-\mathrm{SiO}_{2}, \mathrm{CaO}-\mathrm{SiO}_{2}, \mathrm{SrO}-\mathrm{SiO}_{2}$, and $\mathrm{BaO}-$ $\mathrm{SiO}_{2}$, has been carried out with an argon ion laser beam of $4880 \AA$ for the glassy state and of $4579 \AA$ for the molten state, respectively. New discrete Raman lines have been observed clearly in glassy silicates. The comparison of the spectra with those in the crystallized silicates suggests the presence of four different forms of silicates with basic oxides both in the solid and liquid states, depending on their relative compositions. To our knowledge, this is the first Raman spectral proof on the structural similarity of binary silicates between its solid state and its liquid up to the maximum temperature of $1353 \mathrm{~K}$ except for the preliminary investigation up to 1294 $K$ by Sharma, et al. ${ }^{11}$

Interatomic distances and coordination numbers of silicate atoms have been evaluated from the $X$-ray diffraction measurements. ${ }^{2-4)} \quad$ The vibrational mode of various silicate anions has been deduced from infrared ${ }^{5-7)}$ or Raman spectra. ${ }^{8-11)}$ The analyses on the structure of slags, however, should be carried out with more precise knowledge on various forms of oxygens bound with silicon atoms as functions of slag composition.
\end{abstract}

\section{Sample Preparation and Method of Measure- ment}

In the present investigation, a piece of synthetic quartz glass specimen (Diasil-sp) was used in a form of vitreous pure silica. Binary silicate glasses were prepared from silica powder of $99.9 \%$ purity and from $99.5 \%$ reagent grade alkali metal carbonate or from $99.0 \%$ alkaline earth metal carbonate. These powders were mixed at various compositions and were melted in platinum crucibles in a resistance furnace in vacuum for several hours at temperatures of about $200^{\circ} \mathrm{C}$ above their respective melting points, quenched into a water-cooled copper flat mould, and then ground in a powder form. After these treatments were repeated several times, one could obtain homogeneous, transparent and glassy specimens for Raman spectrometry. The measurement of scattered light was carried out with a double grating monochrometer (Nalumi Model-750Z) at the right angle to the incident beam of an argon ion laser with its intensity of $1300 \mathrm{~mW}$ at $4880 \AA$ for the glassy solid silicate or $310 \mathrm{~mW}$ at $4579 \AA$ for the molten silicate, respectively. The spectrum was obtained by a single photon counting method at low temperatures $\left(<600^{\circ} \mathrm{C}\right)$, whereas a phase sensitive single photon counting method was applied at higher temperatures in order to eliminate the appreciable background radiation from a specimen.

\section{Results and Discussion}

Figure 1 shows the Raman spectra of the quartz glass and the nonstoichiometric systems, $\mathrm{Na}_{2} \mathrm{O}-\mathrm{SiO}_{2}$ and $\mathrm{CaO}-\mathrm{SiO}_{2}$. The spectrum of vitreous silica is the same as those reported by several investigators. ${ }^{8,12,13)}$ The Raman spectra of the $\mathrm{Na}_{2} \mathrm{O}-\mathrm{SiO}_{2}$ system are very similar to those reported by Hass, ${ }^{8)}$ Brawer and White, ${ }^{9)}$ and Konijendijk and Stevels, ${ }^{11)}$ but ours show the explicit dependence of the relative intensities of the Raman lines upon the $\mathrm{Na}_{2} \mathrm{O}$ concentration. No previous report, however, has been given on the spectra of $\mathrm{CaO}-\mathrm{SiO}_{2}$ system, which is a major slag constituent in the production of iron and steel. The silicate formation by mixing $\mathrm{Na}_{2} \mathrm{O}$ with vitreous silica induces a shift of the line at $500 \mathrm{~cm}^{-1}$ toward higher wavenumber. This line has been assigned to the bending mode of Si-O-Si bonding. ${ }^{8)}$ The same shift is observed in $\mathrm{CaO}-\mathrm{SiO}_{2}$ and in other binary systems. The effects of introducing basic oxides $\left(\mathrm{Li}_{2} \mathrm{O}, \mathrm{Na}_{2} \mathrm{O}\right.$, $\mathrm{K}_{2} \mathrm{O}, \mathrm{CaO}, \mathrm{SrO}$ and $\mathrm{BaO}$ ) on the shift of the line around $500 \mathrm{~cm}^{-1}$ may not depend on the species of alkali or of alkaline earth elements but on the composition of a basic oxide. Hence, this shift may be caused by the change in the effective restoring force of the bending angle of Si-O-Si bonding.

According to the spectra in Fig. 1, an increase in the $\mathrm{Na}_{2} \mathrm{O}$ content in the $\mathrm{Na}_{2} \mathrm{O}-\mathrm{SiO}_{2}$ system enhances the intensity of the $1100 \mathrm{~cm}^{-1}$ line up to about 30 mol $\% \mathrm{Na}_{2} \mathrm{O}$ beyond which the intensity decreases, and the $950 \mathrm{~cm}^{-1}$ line appears and continues to grow. In the $\mathrm{CaO}-\mathrm{SiO}_{2}$ system, on the other hand, the corresponding lines are observed at 1070 and $970 \mathrm{~cm}^{-1}$ in the $42 \mathrm{~mol} \% \mathrm{CaO}-\mathrm{SiO}_{2}$ system. Further increase in the $\mathrm{CaO}$ content reduces the intensity of the 1070 $\mathrm{cm}^{-1}$ peak and the $970 \mathrm{~cm}^{-1}$ peak starts to develop. For $\mathrm{CaO}$ contents higher than $42 \mathrm{~mol} \%$, a new line at $870 \mathrm{~cm}^{-1}$ appears. Finally, the spectrum shows three peaks at 870,920 and $970 \mathrm{~cm}^{-1}$ for $59 \mathrm{~mol} \%$ $\mathrm{CaO}$. These lines in the range between 850 and $1100 \mathrm{~cm}^{-1}$ have been attributed to the $\mathrm{Si}-\mathrm{O}$ bond stretching vibration. ${ }^{8)}$

A widely accepted concept is that basic oxides

* $\quad$ Received July 4, 1979.

** Formerly Graduate School, Tohoku University. Now at Oita Works, Nippon Steel Corp., Nishinosu, Oita 870.

*** $\quad$ Faculty of Engineering, Tohoku University, Aoba, Sendai 980.

**** Formerly The Research Institute for Iron, Steel and Other Metals, Tohoku University. Now at Institute of Materials Science, University of Tsukuba, Sakuramura Ten-nodai, Niihari-gun, Ibaraki 305.

***** The Research Institute for Iron, Steel and Other Metals, Tohoku University, Katahira, Sendai 980.

****** Formerly Faculty of Engineering, Tohoku University. Now at Fundamental Research Laboratories, Nippon Steel Corp., Ida, Nakahara-ku, Kawasaki 211. 

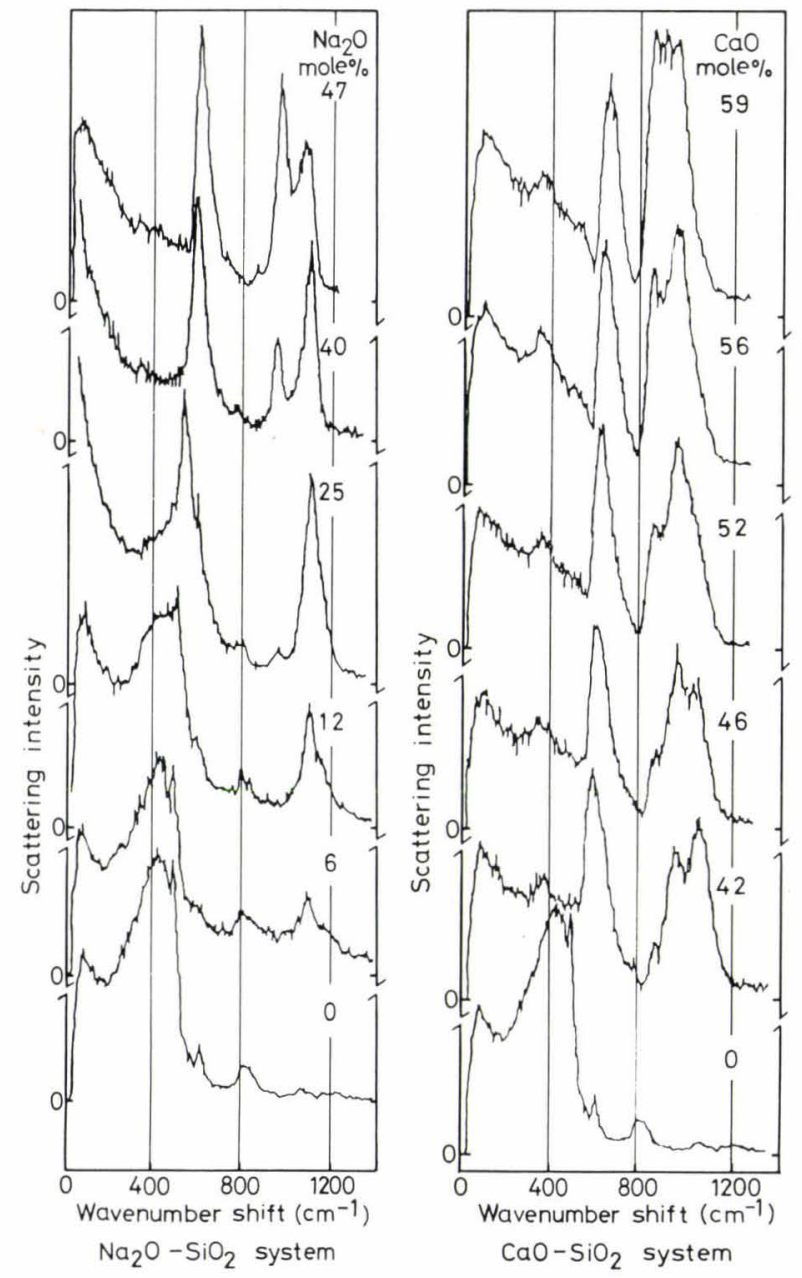

Fig. 1. Raman spectra of glassy $\mathrm{Na}_{2} \mathrm{O}-\mathrm{SiO}_{2}$ and $\mathrm{CaO}-$ $\mathrm{SiO}_{2}$ systems.

modify tetrahedral silica network into four classes as shown in Fig. 2, depending on the type of bonding between oxygen atoms and a silicon atom, namely (a) one non-bridging $\mathrm{O}^{-}$ion, (b) two $\mathrm{O}^{-}$ions, and so forth. Our preliminary measurements on the polycrystalline system show a clear line near $1075 \mathrm{~cm}^{-1}$ in the disilicate $\left(\mathrm{Na}_{2} \mathrm{O} \cdot 2 \mathrm{SiO}_{2}\right)$, which has the (a)type bonding. And another clear line at $985 \mathrm{~cm}^{-1}$ is typical for metasilicate $\left(\mathrm{CaO} \cdot \mathrm{SiO}_{2}\right)$ of the (b)-type bonding. Moreover, the other line at $862 \mathrm{~cm}^{-1}$ is the same as one observed in orthosilicate $\left(2 \mathrm{CaO} \cdot \mathrm{SiO}_{2}\right)$ with $\mathrm{SiO}_{4}^{4-}$ ions of (d)-type. These Raman lines have been observed by previous workers. ${ }^{9,11}$

Our results shown in Fig. 1 suggest the presence of each type of stoichiometric silicates, corresponding to the respective compositions of alkali or alkaline earth metal oxides. For example, in glassy $\mathrm{CaO}-\mathrm{SiO}_{2}$ with $59 \mathrm{~mol} \% \mathrm{CaO}$, the lines at 970,920 , or $870 \mathrm{~cm}^{-1}$ may be assigned to the $\mathrm{Si}-\mathrm{O}$ bond stretching vibration in (b)-, (c)-, and (d)-type ions, respectively. These assignments are based upon the similarity of lattice dynamics between the polycrystalline state and the glassy state.

Non-bridging oxygens in the types (a) to (d) have hardly been distinguished from each other in preceding studies of the silicate slag structure and chemical interactions between slag and metal or gas, but they

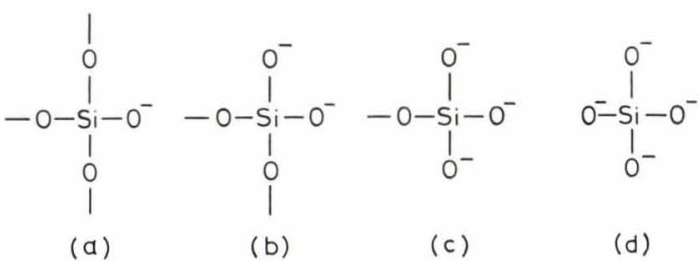

(a) One non-bridging oxygen per one silica tetrahedron

(b) Two non-bridging oxygens

(c) Three non-bridging oxygens

(d) Four non-bridging oxygens, $\mathrm{SiO}_{4}^{4-}$ ion

Fig. 2. Bound oxygens in modified silicates.

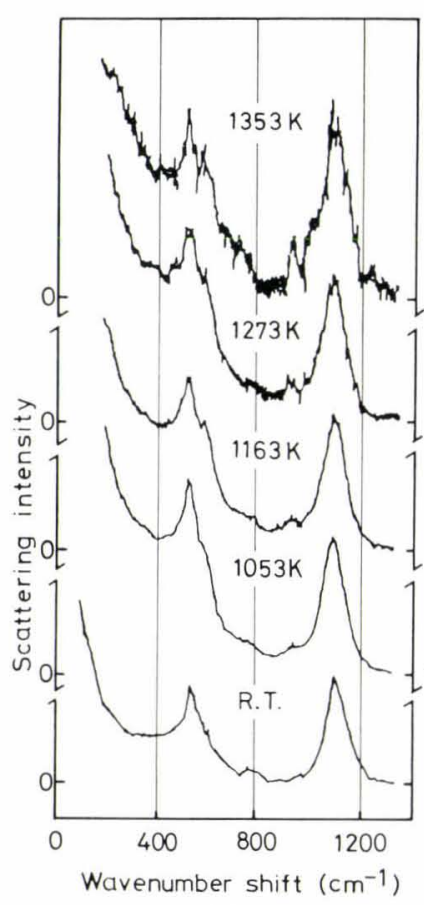

(a)

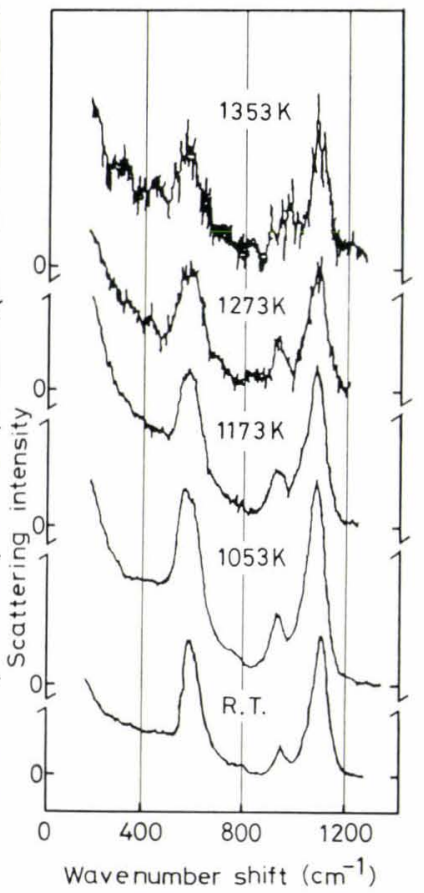

(b) (a) $25 \mathrm{~mol} \% \mathrm{Na}_{2} \mathrm{O}-75 \mathrm{~mol} \% \mathrm{SiO}_{2}$ (melting point: $1103 \mathrm{~K}$ )

(b) $34 \mathrm{~mol} \% \mathrm{Na}_{2} \mathrm{O}-66 \mathrm{~mol} \% \mathrm{SiO}_{2}$ (melting point: $1143 \mathrm{~K}$ )

Fig. 3. Raman spectra of the $\mathrm{Na}_{2} \mathrm{O}-\mathrm{SiO}_{2}$ system in the quenched solid and molten states.

have been regarded as the same kind of a single $\mathrm{O}^{-}$ ion. ${ }^{14)}$ The splitting of Raman bands between 850 and $1100 \mathrm{~cm}^{-1}$ indicates that $\mathrm{O}^{-}$ions are bound in two or more states in Fig. 2.

In Fig. 3, Raman spectra of the $34 \mathrm{~mol}_{0} / \mathrm{Na}_{2} \mathrm{O}-$ $\mathrm{SiO}_{2}$ and $25 \mathrm{~mol} \% \mathrm{Na}_{2} \mathrm{O}-\mathrm{SiO}_{2}$ systems below and above their melting points show little difference between the quenched glassy state and the molten state. The silica tetrahedron complex structures, therefore, are considered to be stable in this system, provided that the solid is in the glassy state and that the $\mathrm{Si}-\mathrm{O}$ bond stretching vibration and the $\mathrm{Si}-\mathrm{O}-\mathrm{Si}$ bending vibration are not thermally affected up to $1353 \mathrm{~K}$.

Furthermore, with the aid of the spectra corresponding to the above-mentioned sub-structures, one may be able to obtain quantitative knowledge on the temperature and pressure dependence of the chemical equilibrium conditions between these four types of 
silica tetrahedron complexes.

\section{Acknowledgements}

The present work was sponsored by the Grant-inAid for Scientific Research from the Ministry of Education for the fiscal years 1976 to 1977.

\section{REFERENCES}

1) S. K. Sharma, D. Virgo and B. Mysen: Carnegie Inst. Year Book, 77 (1977-1978), 649.

2) Y. Waseda and H. Suito: Trans. ISIJ, 17 (1977), 82.

3) Y. Waseda and J. M. Toguri: Met. Trans. B, 8B (1977), 563.

4) Y. Waseda and J. M. Toguri: Met. Trans. B, 9B (1978), 595.

5) D. Kumar, R. G. Ward and D. J. Williams: Trans. Faraday Soc., 61 (1965), 1850.
6) T. Yanagase and Y. Suginohara: J. Japan Inst. Metals, 33 (1969), 443.

7) T. Yanagase and Y. Suginohara: Tetsu-to-Hagané, 57 (1971), 142.

8) M. Hass: J. Phys. Chem. Solids, 31 (1970), 415.

9) S. H. Brawer and W. B. White: J. Chem. Phys., 63 (1975), 2421.

10) N. Iwamoto, Y. Tsunawaki, M. Fuji and T. Hattori: J. Non-Crys. Solids, 18 (1975), 303.

11) W. L. Konijendijk and J. M. Stevels: J. Non-Crys. Solids, 21 (1976), 447

12) P. Flubacher, A. J. Leadbetter, J. A. Morrison and B. P. Stoicheff: J. Phys. Chem. Solids, 12 (1959), 53.

13) M. C. Tobin and T. Baak: J. Opt. Soc. Amer., 58 (1968), 1459 .

14) C.J.B. Fincham and F. D. Richardson: Proc. Roy. Soc., 223 (1954), 40 